\title{
Research Overview on Modern Service Industry Clusters
}

\author{
Chun-Xiang LIU ${ }^{1, a,{ }^{*}, \text { Guo-Feng SHI }}{ }^{1, b}$ \\ ${ }^{1}$ Zhejiang Wanli University, Ningbo City, Zhejiang Province, China \\ acxafa@126.com, ${ }^{\mathrm{a}} 735105398$ @qq.com \\ ${ }^{*}$ Corresponding author
}

Keywords: Modern Service Industry, Research Overview, Current Theoretical Research.

\begin{abstract}
The modern service industry has played a significant role to regional economy and also attracted a lot of attention in the theoretic world. Then this article has made a relative comprehensive study on current theoretical and empirical research on modern service industry clusters. This article has drawn the conclusion that current researches are mainly on the macro vision. The study on some typical regions should be broadened and encouraged.
\end{abstract}

\section{Related Definition}

The modern service industry is an internationally prevailing concept of industrial classification. It involves the provision of services rather than goods and normally includes the consumer services industry and the producer services industry. A modern service indu stry cluster is a mini CBD (MCBD) with strong functions of modern service industry clustering. Based on traffic hubs and information network, it is planned and designed in line with the modern urban development concept. It takes office buildings as carriers to effectively and properly centralize professional supporting service facilities in a certain district, which is characterized by reasonable spatial arrangement, complete supporting functions, convenient transport, creative building styles, harmonious ecological environment and human-oriented principle. This paper will focus on analyzing domestic and foreign researches on modern service industry clusters to provide theoretical references for related scholars.

\section{Current Theoretical Research on Modern Service Industry Clusters}

"Modern service industry", as defined by foreign scholars, includes the knowledge intensive business services and the producer services. In term of the knowledge intensive business services (KIBS), Miles (1995) defines it as a firm or organization which relies heavily on professional knowledge related to a specific discipline and which supplies intermediate products and services that are knowledge based to the society and clients.

Hertog (1998) argues that the most important task of KIBS is to provide knowledge-related services during the innovation process. Kemppila and Mettanen (2004) characterize KIBS as "knowledge is important input of a service", "services are heavily based on professional competence and knowledge" and "clients actively interact with enterprises or organizations". OECD categorizes the knowledge intensive business services into the information service industry, the financial service industry, the education service industry, the professional technology service industry and the health service industry.

Machlup (1962) indicates that the producer services are characteristic of the input of knowledge. Greenfield (1966) explains the producer services from the perspective of service objects and points out that they actually serve producers, not end consumers. Marshall and other scholars argue (1987) that the producer services shall include provision of information processing related, physical commodities related and personal support related services.

Singlemann (1978) categorizes the service industry into four sectors of producer services, distributive services, social services and personal services according to the application of service products. Grubel and Walker (1989) argue that producer services are intermediate input for producers of other products and services. Through investigations and researches on enterprises of producer 
services clusters in London, D. Keeble and other scholars (1998) found that the mechanism of collective learning could absorb knowledge through the informal social network, the cooperation between enterprises in the park could formally advance learning, and the flow of skills/labor could promote knowledge flow.

In terms of domestic researches, the Report to the 15th NCCPC put forward the concept of "modern service industry" for the first time. Currently, theoretical researches focus on the boundary of the modern service industry and involve three viewpoints: (1) the modern service industry is modern producer services, (2) the modern service industry incorporates an emerging information-based service industry and an upgraded traditional service industry, (3) the definition of the modern service industry, by its nature, shall depend on the spillover effect of the modern service industry on other industries.

Representative researches: Huang Fanhua (2001) argues that the modern service industry, also called as the emerging tertiary industry, normally is comprised of information service industry, financial insurance industry, real estate and community service industry, tourist industry, logistics industry, etc.. He studied the case of Nanjing and analyzed issues on economic globalization and industrial structure optimization. Xu Guoxiang and Chang Ning (2004) indicate that the modern service industry emerges at the stage of highly developed industrialization, and knowledge intensive producer services, mainly dependent on electronic information technology and modern management concepts, generally include eight categories of logistics \& express, information transmission/computer services and software, e-commerce, financial insurance, real estate, leasing and commercial services, scientific research/technology research/experiment, distance education.

Liu Zhong (2005) argues that the broad modern service industry covers the upgraded traditional service industry and the emerging service industry, while the narrow definition highlights information and knowledge intensive of industries. Gu Naihua (2006), based on the standard of spillover functions, groups the modern producer services industry, the traditional producer services industry after upgrading of information technology and the modern consumer services into the modern service industry. Li Zhiping and Bai Qinghua (2006) point out that the modern service industry is relative to the traditional service industry. They have the same definition as Xu Guoxiang and Chang Ning have. The difference is that the former does not equal the modern service industry to producer services. In 2008, the Statistics Bureau of Guangdong Province differentiated nine sectors of the modern service industry: information transmission, computer service and software, finance, real estate, leasing and commercial service, scientific research, etc.

In addition, some scholars theoretically researched the cause, mechanism and existence of the modern service industry clusters. Huang Yong (2009) introduced the experience of constructing service industry clusters in Shanghai and Jiangsu, and conducted in-depth researches on the definition, key development, operations management and supporting measures of the service industry clusters, which has laid a theoretical foundation for Zhejiang to issue its modern service industry clusters plan. Based on the researches on the dynamic mechanism and cluster development features, Dai Wen and Qin Yuanjian (2005) put forward three development modes of the modern service industry clusters: virtual industry clustering, industrial clusters' ecologization, and industrial clusters' chains.

Zhang Shulin (2006 and 2007) argues that the modern service industry, as an emerging service industry, puts an emphasis on producer services. The modern service industry shall have six clustering effects: external economy, competitive industries and regional competition, self-reinforcement, etc.. Meanwhile, he indicates that the urbanization process has a positive feedback effect on the modern service industry clusters and vice versa.

Jiang Sangeng (2008 and 2009) points out that the modern service industry clusters, different from producer services, are located in central business districts in metropolises. Therefore, CBD development experience shall be referenced to construct modern service industry clusters. Li Zhiping and Bai Qinghua (2008) agree that the modern service industry is highly centralized in central districts in internationalized cities. They have conducted researches on the formation mechanism of modern service industry clusters in big cities. Fu Ming (2009) carried out game analysis and cause 
analysis on the modern service industry clusters from the perspective of product differentiation producing monopoly.

\section{Current Empirical Researches on the Modern Service Industry Clusters}

Shen Qin (2012) calculated the location quotient of the producer services in Jiangsu from 2003-2010, structured an indicator system of influence factors on producer services clusters, and utilized stata 11.0 software to conduct empirical analysis on panel data of influence factors on the producer services. According to the researches, factors of economic growth, structure of the tertiary industry, human resources and transport infrastructure remarkably promote the clustering of producer services, while the scale of government has a crowding-out effect. Factors of gross fixed assets investments, value of industrial output, city size and communication technology have little effect on the clustering of producer services in Jiangsu.

Dong Xinling (2012) selected five variables of clustering of the manufacturing industry, clustering of the service industry, land rent, high-quality human resources and infrastructure to conduct regression analysis on influence factors involving the clustering of producer services throughout the national except Beijing and Shanghai. He sorted these factors which impact the clustering of producer services within different regions. Moreover, he selected representative industrial provinces of Guangdong, Jiangsu, Zhejiang and Shandong to verify the regression results in connection with the per capita added value of each industry. He concluded that producer services are not interactively developed with the manufacturing industry and the service industry.

After SWOT analysis on the modern service industry of Guangdong, Zheng Jingshu and Yuan Fei (2009) found related problems: low GDP proportion, little interaction with the manufacturing industry, low capability of innovation and policy restrictions. Xu Yinzhou (2009) argues that the Pearl River Delta shall lead in the development of producer services under guidance of the guideline. Xiao Yi (2008) advises that Guangdong modern service industry shall make reference to the matured driving model in developed countries, and focus on key industries and competitive industries.

Pan Chaoxiang and Xu Ling (2008) suggest that to speed up the development of the modern service industry in Jiangsu requires the improvement of policy adaptability, competitiveness of producer services, absorption of transferred international service industries and radiation of modern service industry clusters. Liu Jiangang (2004) analyzed the current modern service industry of Tianjin and proposed to speed up the development of Haihe and promote the modern logistics industry, finance industry and information service industry. Zhu Xiaoqing (2007) analyzed the development theories related to world urban core industry clusters and the modern service industry, and discussed the selection of core service industry clusters of Beijing based on its current modern service industry development.

Chen Lin (2008) centered on discussing the driving force and conditions of the formation and development of Beijing modern service industry clusters. After comparative research on the development mode of modern service clusters in New York, London and Tokyo, Yang Yaqin and Wang Dan (2005) proposed that the development of leading industries, guidance and support by policies, gathering of professional talents and demands on the modern service industry are significant for the development of the modern service industry. Chen Shuxiang and Gong Jian (2007) compared key indicators of the modern service industry of Beijing, Tianjin, Shanghai and Chongqing, and gave a series of suggestions on expediting the development of the modern service industry.

There are a small quantity of empirical research documents on industrial clustering and the indicator system of the modern service industry, as representative researches include followings: Bao Xiaowen (2011), taking Shanghai as an example, analyzed the spatial arrangement and clu stering effects of urban service industry clusters. Jin Rongxue and Xu Guangyue (2009) carried out empirical analysis on provincial panel data of China, and found that the clustering of the modern service industry in East China, Middle China and West China had positive relationships with economic development, and that the effects which the clustering of the modern service industry had on economic growth kept reducing from the east to the west. Wang Xiaodong (2008) calculated the concentration ratio, investigated the concentration of the logistics industry of China, and analyzed 
related influence factors. Li Yanhua, Liu Xielin and Liu Jianbing (2009) designed the innovation capability measurement indicator system of the modern service industry, and evaluated the innovation capability of the modern service industry of Beijing.

\section{Comments on Current Researches}

After above materials involving the modern service industry clusters are reviewed, it can be learnt that the matured theories on industrial clustering abroad mainly relate to the manufacturing industry, while there is small in-depth researches on the modern service industry clusters overseas, which requires further systemization. Some of domestic scholars, based on regional development, analyzed the current development, location advantages and inter-regional comparison. These researches cover different provinces and thesis, but mainly focus on Pearl River Delta, Yangtze River Delta and Jing-Jin-Ji Region. On the whole, domestic researches on the modern service industry are more theoretical and less empirical, especially lacking in systematic researches on the modern service industry clusters in typical regions.

\section{Acknowledgement}

This research was financially supported by the Academic Climbing Project from Education Department of Zhejiang Province with the number of pd2013324 and the Soft Science Subject of Zhejiang Province with the number of 2013C35022.

\section{References}

[1] Han LiMin, Wang AiXiang. Expanding agricultural utilization of foreign capitals and advancing agriculture's internationalized process. Economic Research Consults, vol.50, pp.45-48, 2002.

[2] Wu Qiai. Utilizing of Foreign Capitals in the field of Agriculture Needs Innovation of Mechanism. Survey and Study of the World, vol.5, pp. 36-38, 2001.

[3] Zhang HanLin, WTO and Trade Disputes on Agricultural Products, Shanghai: Shanghai People's Press, 2002.

[4] Ji-kun Huang, Scott Rozelle, Francis Tuan. Dancing with the Dragon: Developments in Chinese Agriculture \& the Implications for Australia's Relationship with China. http://www.cafte.gov.cn/english/AGRICULTURE_BRIEFING/CONFENTS/4204.asp, 2007.

[5] Liu Chunxiang, Zhang Liping. Empirical Analysis of Innovation Capability of Traditionally Competitive Industries of Ningbo. Industrial Technology \& Economy, vol 4, pp. 128-135, 2010.

[6] Jia Shenghua, Shu Libing, Industrial Evolution, Collaborative Innovation and Continuous Growth of Private Enterprises: Theoretical Research and Zhejiang Experience, Zhejiang University Press, 2007.

[7] Tian Jixin, Jia Shenghua. Capability Construction and Upgrading Strategy of Cluster Enterprises in the Network Perspective: Theoretical Analysis and Empirical Research. Zhejiang University Press, 2008.

[8] HumPhrey J, Sehmitz H. Governance and Upgrading: Linking Industrial Cluster and Global Value Chain Research. Sussex: University of Sussex, 2000.

[9] Cheng Xuetong, Wang Zuqiang, Li Tao, Analysis on the Growth Model of Cluster-based Private Enterprises, China Economic Publishing Press, 2004.

[10] Xu Chenghong, Researches on Industrial Clusters and Competitiveness of the West Region, SWUFE Press, 2006.

[11] Porter, M. E. Clusters and the New Economics of Competition. Harvard Business Review, 
1998(Nov.-Dec.):77-90.

[12] Coffey W.J., Baily A. Producer Services and Systems of Flexible Production. Urban Studies, 1992,29(3): 857-868.

[13] Daniels, P. W. Locational dynamics of producer and consumer services. Ch. 8 in Service Industries: A Geographic Appraisal. London: Methuen. 1985.

[14] Friedman J. World Cities Revisited: Comment. Urban Studies, 2001, 38(13): 2535-2536.

[15] Fujita, M. Krugman, P. and Venables, A.J. The Spatial Economy: Cities, Regions, and International Trade, 1999. Cambridge MA: MIT Press.

[16] Fuchs V R. The service economy. Columbia: Columbia University Press, 1968: 12-15.

[17] Howells, Green. Location, Technology and Industrial Organization in UK services. Progress in Planning, 1986, (2).

[18] Hatch C. Learning From Italy's Industrial Renaissance. The Entrepreneurial Economy, 1987,(1): 4-11.

[19] Illeris S. The Service Econom: A geography Approach. Chichester: John Willey \& Sons, 1996.

[20] Illeris S. Producer services: the key factor to economic development. Entrepreneurship and regional development, 1989, (1).

[21] Lundvall, B, Borras, S. The Global Learning Economy: Implications for Innovation Policy. TSER Programmer Report, Commission of the European Union, 1998,(1). 